\title{
Study on the Morphology and Fiber Properties of Nanoclay Added Polyvinyl Alcohol (PVA) Nanofibrous Mats: Effect of Mechanical Dispersion
}

\author{
Reyhan Keskin ${ }^{1 *}$ Muhammed Zahid Koç² \\ 1. Textile Engineering, Engineering Faculty, Pamukkale University, PO box 20070, Denizli, Turkey \\ 2. Textile Engineering, The Graduate School of Natural and Applied Sciences, Pamukkale University, PO \\ box 20070, Denizli, Turkey \\ *E-mail of the corresponding author: reyhank@pau.edu.tr
}

\begin{abstract}
In this study, polyvinyl alcohol (PVA) polymer and Cloisite 15A, a modified form of organo Montmorillonite nanoclay, are used to produce nanofibrous mats via electrospinning technique. Pure PVA nanofibrous mats from mechanically stirred polymeric solutions at 8,10 and $12 \mathrm{wt} \%$ PVA percents; and nanoclay added PVA nanofibrous mat samples are produced at increased nanoclay weight/ polymer weight ratios (1/13, 1/11, 1/9 and 1/6) using several mechanically stirred nanoclay-PVA solutions at various proportions of nanoclay and PVA polymer wt \% in solutions. The viscosities, surface tensions and electrical conductivities of solutions were measured. FESEM (Field Emission Scanning Electron Microscopy) analysis, fiber diameter distribution with Image J software analysis and tensile testing was applied to nanofibrous samples. Increased polymer concentration led to bead-free nanofibrous PVA mats. EDX analysis approved nanoclay is present in samples produced from nanoclay added PVA solutions. Mechanical stirring for nanoclay dispersion enabled smooth nanofibrous structures only in low $(1 / 13)$ nanoclay weight/ polymer weight ratios and showed very little tensile increase from $1 \mathrm{wt} \%$ clay loading to $2 \mathrm{wt} \%$ addition. A direct increase in tensile strength wasn't achieved with nanoclay content increase in PVA nanofibrous mats; this might be due to the effect of poor nanoclay distribution adversely affecting tensile results. Morphological analysis proved that nanofibrous structures were far away from smooth fiber structures as they transformed from smooth nanofibers into non-uniform fibrous structures at increased nanoclay weight/ polymer weight ratios in nanoclay added PVA samples.
\end{abstract}

Keywords: nanofibrous mat, electrospinning, polyvinyl alcohol (PVA), nanoclay, mechanical dispersion

DOI: $10.7176 /$ CPER/62-08

Publication date: May $30^{\text {th }} 2020$

\section{Introduction}

Nanofibers are fibers having diameters in nano scale (Fong et al. 1999). Many solutions of polymers, especially engineering polymers, are eligible to be spun into nanofibers and nano structured mats. Polymeric nanofibers exhibit high surface to volume ratios (Ramakrishna et al. 2006) and they have high aspect ratios (Ko et al. 2004), high mechanical properties (Subbiah et al. 2004), wound treatment ability (Abdelhady et al. 2015) and are highly porous when produced in mat forms (Burger et al. 2006) as well. Nanofibers and nanofibrous mats, being interesting nanotechnology textile products, find several applications such as wound dressings for fast healing (Chen et al. 2017), ultrafiltration (Prince et al. 2012), protective clothing production (Haider et al. 2015), drug delivery systems and scaffolds in tissue engineering (Ko et al 2017).

Functionalization of nanofibers is a huge extension of nanofibrous materials research (Wang 2013, Hussain 2016); and among functionalization techniques addition of several nanoparticles into nanofibers attracted attention of many researchers. Various nanoparticles used to add in nanofibers are nanocarbons (carbon nanotubes, graphenes, fullerenes) and nanoclays. Nanoclays are outstanding nanoparticles as they already occur in nature in nano scale such as Montmorillonites (Kaboorani 2013).

A huge challenge that is faced with clay nanoparticle addition into polymeric structures is the dispersion problem. Nanoclays are materials composed of many thin layers stacked together; mixing methods can help to drive apart clay layers and enable dispersed nanoclay structures in solutions and polymer phases (El-Qadhi 2013). As clay nanoparticles are layered structures and tend to form aggregates in mixtures and solutions, mixing techniques are used to achieve nanoclay dispersion in polymer solutions (Agubra 2013). 
Nanoclay addition into nanofibrous structures with different types of nanoclays in several polymeric host nanofibers is a magnet study field for nanofibrous material applications. Roghani-Mamaqani et al. (2010) dispersed clay in polystyrene (PS) and produced nanofibers in 450-650 nm diameters and they concluded that nanoclay increased thermal stabilities of nanofibers compared to neat PS nanofibers (Roghani-Mamaqani et al. 2010).

Saeed \& Park (2012) tested mechanical and thermal properties of nanoclay added Nylon-6 nanofibers. They observed that the thermal properties increased with nanoclay addition; however, mechanical properties decreased whe nanoclay content increased and concluded it might be caused by aggregation of nanoclay at high content ratio of $5 \mathrm{wt} \%$ clay (Saeed \& Park 2012).

Neppali et al. (2013) studied the effect of nanoclay on polyvinylidene fluoride (PVDF) nanofibers and found that electrospinning did not essentially increase the dispersion of clay within the polymer, clay content decreased the crystallinity degree and thicker nanofibers formed with increased nanoclay content (Neppali et al. 2013).

Liu et al. (2014) analyzed mechanical properties of nanoclay reinforced nanofibers by mechanically mixing nanoclay and polyvinyl alcohol polymer granules in water at 8/3,10/3, 10/5, 10/7 and 12/4 weight ratios (the PVA weight percent concentration in the solution/nanoclay weight concentration with respect to PVA). Researchers observed more beads and irregularities on nanoclay added nanofibers compared to pure PVA nanofibers. Liu et al observed decreases in tensile and tear strengths of nanoclay added polyvinylalcohol nanofibers; this mechanical decrease might be due to agglomoration or inadequate dispersion of nanoclays inside the polymer (Liu et al. 2014).

Previous studies indicate that addition of different nanoclay percents in varying amounts (lower or higher percents) in polymeric matrices cause detrimental decreases in mechanical properties at high percents of nanoclay loading although increased tensile results are obtained at low content ratios of clay loading in polymer (Lobos et al 2014). Based on studies in literature, this study aims focusing on addition of nanoclay in increasing percents in polyvinyl alcohol polymer. In this study, the effect of Cloisite 15A nanoclay addition in PVA nanofibrous mats was investigated by increasing nanoclay/polymer weight ratios in final nanofibrous mat samples. Morphological, mechanical and fiber properties of produced nanofibrous mats were investigated in this study.

\section{Materials and Method}

Partially hydrolyzed polyvinylalcohol (PVA) polymeric granules having a molecular weight at approximately 70 $000 \mathrm{~g} / \mathrm{mol}$ were purchased from Merck. The Cloisite 15A nanoclay is a modified organo montmorillonite type, used in the study is from Southern Clay Products Inc. (USA) and has 3,63 nm lamellar distance. The solvent used during solution preparation of PVA was distilled water having dielectric constant at 80 and electrical conductivity at $0.06 \mu \mathrm{S} / \mathrm{cm}$.

The PVA solutions were prepared with the aid of magnetic stirring and dissolving specific weights of PVA granules in distilled water; while nanoclay added PVA solutions were prepared with the aid of magnetic stirring and dissolving first the nanoclay then the polymer in specific weights for each sample (Park et al 2010). Magnetic stirring was completed at $80^{\mathrm{D}} \mathrm{C}$ in 3 hours at $600 \mathrm{rpm}$; and the solutions were kept overnight at room temperature on the magnetic stirrer at $200 \mathrm{rpm}$ with the aim of keeping stable and homogenous solutions for production. In solutions having nanoclays, nanoclays used to redeposit on the bottom of the sample bottles as solutions are left for long hours without stirring. The polymer and water weights of pure polymer solutions are listed in Table 1 and proportion of solutions (polymer and nanoclay weights) and the nanoclay/polymer ratios in resulting samples as "Nanoclay wt\% / final fiber weight" in mechanically stirred nanoclay added PVA solutions are given in Table 2.

Prior to electrospinning, the viscosities and electrical conductivities of polymeric solutions prepared were measured respectively with Brookfield DV50 viscometer and ADWA brand AD32 model conductivity meter. There are many methods of measuring surface tension such as capillary rise method, stallagmometer method, drop weight method, Wilhelmy plate method, ring method and several dynamic methods. We started measurements with a $3.5 \mathrm{ml}$ stallagmometer and repeated measurements with the droplet method and observed a similarity in results. As the stallagmometer method is very time consuming, we completed surface tension measurements with the droplet method using Pasteur pipettes. The surface tensions of solutions were calculated according to the droplet weight method using the formula given in Equation 1.

Surface tension of solution $=\frac{72.8 \times M_{\text {water }}}{M_{\text {solution }}} \ldots \ldots \ldots \ldots \ldots \ldots \ldots$ (1) 
Where:

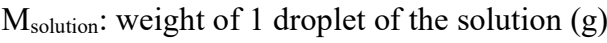

$\mathrm{M}_{\text {water }}$ : weight of 1 water droplet ( $\mathrm{g}$ )

To produce pure PVA nanofibrous mats and nanoclay added PVA samples, the equipment used for electrospinning was a laboratory scale one-nozzled electrospinning machine (Inovenso, model Ne 100), shown in Figure 1, which is capable of working at high voltages up to $40 \mathrm{kV}$ at $0,125 \mathrm{~mA}$.

FESEM (Field Emission Scanning Electron Microscopy) analysis was done at backscattering mode with nanofibrous samples. The equipment used for FESEM analysis was a Zeiss Supra 40 VP model. Fiber diameter distributions were acquired through processing FESEM images on Image $\mathrm{J}$ software program using around 100 fibers in each image.

Tensile testing was conducted to evaluate the effect of nanoclay addition using magnetic stirring on mechanical properties of nanofibrous mats. Tensile strength tests were conducted on a Tinius Olsen universal testing machine model H10KT according to the method described by Molnar et al 2012; samples were cut at 6 mm width and 20 $\mathrm{mm}$ length and were mounted on cartoon frames prior to testing (Figure 2). Samples were conditioned in testing laboratory having conditions of $57 \%$ humidity and $20{ }^{\mathrm{D}} \mathrm{C}$ prior to testing. Mean values and deviations for 10 repetitions are given in Table 5 for tensile testing.

\section{Results and Discussion}

The viscosity and electrical conductivities of pure PVA solutions are given in Table 3 . The viscosity and electrical conductivities of mechanically dispersed nanoclay-PVA solutions are given in Table 4a whereas viscosity and electrical conductivities with nanoclay addition in solutions are summarized in Table 4b; viscosity increase with nanoclay addition was seen when nanofibers were produced from PVA polymers having different molecular weights (Ji et al 2009).

In Table 3, increasing concentration leads to an increase in viscosity; a very slight increase in surface tension and a very slight increase in electrical conductivity of the solution. As polymer concentration increased, viscosity increased obviously; surface tension slightly decreased while electrical conductivity slightly increased at increasing solution polymer concentrations. In Table $4 \mathrm{a}$, it is not possible to find a correlation between increased nanoclay weight percent in final nanofibrous mats and viscosity as polymer amount is decreasing and causing another effect on viscosity; however, in Table $4 \mathrm{~b}$ it is obvious that addition of nanoclay in solutions increases solution viscosity and slightly increases electrical conductivity. Viscosity is having importance on fiber appearance and there is an optimum viscosity at which bead free nanofibers can be produced (Fong et al, 1999); in this study we obtained bead-free nanofibers when viscosity reached $221 \mathrm{cP}$ in value.

FESEM images and fiber diameter distribution graphs of pure PVA electrospun samples A7, B7 and C5 are given respectively in (a), (b) and (c) parts of Figure 3. Sample A7 has large round shaped beads at high quantity, sample B7 has very few and ribboned beads on the nanofibrous structure, while sample C5 has smooth fibers and no beads on the structure. Solution concentration, which increases viscosity, is reported to be affecting fiber formation in electrospinning and with increasing concentration the fiber morphologies are changed from beaded to uniform fiber structures (Zhang et al 2005). In Figure 3, nanofibrous structures are visible and beads on nanofibers at samples A7 and B7 are disappearing as solution concentration increases in sample C5. The average nanofiber diameter values obtained from Image $\mathrm{J}$ analysis are given in Table 5 for pure PVA samples produced from solutions at increasing polymer concentrations. Nanofibers are produced in the 135-160 nm range and the concentration increase causes an increase in fiber thicknesses when beads are disappearing. Literature studies show fiber thickness increases with increasing concentrations (Zhang et al 2005; Suphaphol \& Chuangchote 2007). At nanofibrous mats (samples A7 and B7) produced from lower viscositiy having solutions (respectively, sol A and sol B) beads are observed. At sample C5 produced from higher viscosity having $12 \mathrm{wt} \%$ solution (sol C) beads disappeared; higher viscosity enables fiber formation without beads (Fong et al 1999).

FESEM images and fiber diameter distribution graphs, which are obtained from Image J and Diameter J softwares, of nanoclay added PVA electrospun samples K5, H2, G7 and I1 are given respectively in (a), (b), (c) and (d) parts of Figure 4. In Figure 4, it is clear that increasing clay contents shows increased beading in size and quantity of the nanoclay added nanofibrous structures. Similar results of increased beads on PVA nanofibers were mentioned in literature (Ristolainen et al 2005, Ji et al. 2009, Liu et al. 2014). In Figure 5, EDX (Energy Dispersive X-ray) 
analysis of $18 \mathrm{wt} \%$ mechanically stirred PVA solution on aluminum substrate, nanofibrous mat electrospun from $18 \mathrm{wt} \%$ mechanically stirred PVA solution, mechanically stirred $1 \mathrm{wt} \%$ nanoclay added $18 \mathrm{wt} \%$ PVA solution and sample deposited on aluminum foil from mechanically stirred $18 \mathrm{wt} \%$ PVA- $2 \mathrm{wt} \%$ nanoclay is given. EDX analysis confirms PVA nanofibrous samples deposited on aluminum foils are composed of only carbon and oxygen elements and gives aluminum picks coming from the foil substrate; and as well, EDX analysis approved nanoclay is present in samples produced from nanoclay added PVA solutions.

The average diameter values of nanofibrous mats calculated from Image J analysis are given in Table 6 for nanoclay reinforced PVA nanofibrous samples produced using solutions at increasing nanoclay weight percentages compared to total weight of produced samples. The nanoclay added samples change from smooth and bead free structures into fiber networks with large beads, which might be due to nanoclay incorporation to the samples. In a previous literature study, increased content of clay percents in nanofibers caused aggregation in fiber formation and has an effect of adding beads to the fiber structures (Yeum et al, 2011).

The tensile testing results of samples are given in Table 7 . The tensile force values of nanofibrous mats electrospin from $18 \mathrm{wt} \%$ PVA, $18 \mathrm{wt} \%$ PVA- $1 \mathrm{wt} \%$ nanoclay, $18 \mathrm{wt} \%$ PVA- $2 \mathrm{wt} \%$ nanoclay and $18 \mathrm{wt} \%$ PVA- $3 \mathrm{wt} \%$ nanoclay were $2.85,2.00,2.15$ and $1.15 \mathrm{~N}$, respectively, and the elongation percentages were $3.80,8.75,13.20$ and $5.22 \%$, respectively. Although among nanoclay added samples, tensile force shows first an increase then a decrease with increased nanoclay weight percentages; tensile forces, as a result tensile strengths, of nanoclay added samples are lower than pure PVA nanofibrous mats; the decrease in tensile strength with nanoclay incorporation might be due to random distribution of nanoclay in PVA polymer (Liu et al 2014). The decrease with increased nanoclay weight percentages from $2 \mathrm{wt} \%$ to $3 \mathrm{wt} \%$ addition might be occurred due to nanoclay aggregation at the higher content of $3 \mathrm{wt} \%$ clay loading (Saeed 2012). The tensile properties of nanoclay added samples were lower than pure polymeric samples; however, at low clay contents (comparing $1 \mathrm{wt} \%$ and $2 \mathrm{wt} \%$ loadings) tensile force showed a slight increase with clay addition, while at higher clay content (comparing $2 \mathrm{wt} \%$ and $3 \mathrm{wt} \%$ loadings) tensile force showed a sharp decrease, which might be due to aggregation (Lobos et al 2014).

\section{Conclusion}

Nanoclay added PVA nanofibrous samples were electrospin from nanoclay particle distributed solutions. In this study, nanoparticle distribution inside the polymeric solutions was aimed to achieve by mechanically stirring. The morphology, fiber properties and tensile properties of electrospun pure PVA and nanoclay added PVA nanofibrous samples were investigated according to increased concentrations.

Nanoclay added samples were compared with pure PVA nanofibrous samples. Pure PVA nanofibrous samples had bead formation at samples electrospin from low viscosity polymeric solutions, beads disappeared at increased viscosity values of polymer solutions. Smooth and bead free nanofibrous samples were achieved using $12 \mathrm{wt} \%$ pure PVA solution. EDX analysis characterization indicated that nanoclay is present in nanofibrous mats produced from mechanically stirred nanoclay added PVA solutions.

The tensile properties did not show a direct increase compared to pure PVA nanofibrous sample with nanoclay addition, although slight increase in tensile force was achieved among nanoclay added samples at low contents.

Both results from FESEM images and tensile tests indicate poor nanoclay distribution inside the PVA polymer. Suggested future works include employing different mixing methods to enable better dispersion of nanoclay particles among polymer chains.

\section{References}

Abdelhady, S., Honsy, K. M., \& Kurakula, M. (2015), "Electro Spun- Nanofibrous Mats: A Modern Wound Dressing Matrix with a Potential of Drug Delivery and Therapeutics", Journal of Engineered Fibers and Fabrics, 10(4), 179-193.

Agubra, V., Owuor, P., \& Hosur, M. (2013), "Influence of Nanoclay Dispersion Methods on the Mechanical Behavior of E-Glass/Epoxy Nanocomposites”, Nanomaterials, 3(3), 550-563.

Al-Qadhi, M., Merah, N., Khan, Z., Mezghani, K., Gasem, Z., \& Adinoyi, M. J. (2012), "Effect of sonication and high shear mixing parameters on nanoclay dispersion in epoxy", ECCM 2012 - Composites at Venice, Proceedings of the 15th European Conference on Composite Materials.

Burger, C., Hsiao, B. S., \& Chu, B. (2006), "Nanofibrous Materials and Their Applications”, Annual Review of Materials Research, 36(1), 333-368. 
Chen, S., Liu, B., Carlson, M. A., Gombart, A. F., Reilly, D. A., \& Xie, J. (2017), "Recent Advances in Electrospun Nanofibers for Wound Healing", Nanomedicine, 12(11), 1335-1352.

Fong, H., Chun, I., \& Reneker, D. H. (1999), "Beaded Nanofibers Formed During Electrospinning”, Polymer, 40(16), 4585-4592.

Haider, A., Haider, S., \& Kang, I. K. (2018), "A Comprehensive Review Summarizing the Effect of Electrospinning Parameters and Potential Applications of Nanofibers in Biomedical and Biotechnology", Arabian Journal of Chemistry, 11(8), 1165-1188.

Hussain, M. M., \& Ramkumar, S. S. (2006), "Functionalized nanofibers for advanced applications", Indian Journal of Fibre and Textile Research, 31(1), 41-51.

Ji, H. M., Lee, H. W., Karim, M. R., Cheong, I. W., Bae, E. A., Kim, T. H., Islam, M.S., Ji, B.C. \& Yeum, J. H. (2009), "Electrospinning and Characterization of Medium-molecular-weight Poly(vinyl Alcohol)/High-molecularweight Poly(vinyl alcohol)/ Montmorillonite Nanofibers", Colloid and Polymer Science, 287(7), 751-758.

Kaboorani, A., Riedl, B., \& Blanchet, P. (2013). Ultrasonication technique: A method for dispersing nanoclay in wood adhesives. Journal of Nanomaterials, 1(1), 1-9.

Ko, F. K., \& Wan, L. Y. (2017), "Nanofiber Technology: Bridging the Gap Between Nano and Macro World", Nanomaterials Handbook, Second Edition, 603-628.

Liu, W., Yee, S., \& Adanur, S. (2014), "Properties of Electrospun PVA/Nanoclay Composites", Journal of the Textile Institute, 105(4), 423-429.

Neppalli, R., Wanjale, S., Birajdar, M., \& Causin, V. (2013), “The Effect of Clay and of Electrospinning on the Polymorphism, Structure and Morphology of Poly(vinylidene fluoride)", European Polymer Journal, 49(1), 9099.

Prince, J. A., Singh, G., Rana, D., Matsuura, T., Anbharasi, V., \& Shanmugasundaram, T. S. (2012), "Preparation and Characterization of Highly Hydrophobic Poly(vinylidene fluoride) - Clay Nanocomposite Nanofiber Membranes (PVDF-clay NNMs) for Desalination Using Direct Contact Membrane Distillation", Journal of Membrane Science, 397(1), 80-86.

Ramakrishna, S., Fujihara, K., Teo, W. E., Yong, T., Ma, Z., \& Ramaseshan, R. (2006), "Electrospun Nanofibers: Solving Global Issues", Materials Today, 9(3), 40-50.

Ristolainen, N., Heikkilä, P., Harlin, A., \& Seppälä, J. (2006), "Poly(vinyl alcohol) and Polyamide-66 Nanocomposites Prepared by Electrospinning", Macromolecular Materials and Engineering291(2), 114-122.

Roghani-Mamaqani H., Haddadi-Asl V., Najafi M. \& Salami-Kalajahi M. (2011), "Preparation of NanoclayDispersed Polystyrene Nanofibers via Atom Transfer Radical Polymerization and Electrospinning", Journal of Applied Polymer Science, 120(3), 1431-1438.

Saeed K. \& Park S.Y. (2012), "Effect of Nanoclay on the Thermal, Mechanical, and Crystallization Behavior of Nanofiber Webs of Nylon-6",Polymer Composites, 33(2), 192-195.

Subbiah, T., Bhat, G. S., Tock, R. W., Parameswaran, S., \& Ramkumar, S. S. (2005), "Electrospinning of Nanofibers", Journal of Applied Polymer Science, 96(2), 557-569.

Supaphol, P., Chuangchote, S. (2008), "On the Electrospinning of Poly(vinyl alcohol) Nanofibers Mats: A Revisit", Journal of Applied Polymer Science 108(2), 969-978.

Wang, P., Wang, Y., \& Tong, L. (2013), "Functionalized Polymer Nanofibers: A Versatile Platform for Manipulating Light at the Nanoscale”, Light: Science and Applications, 2(e102), 1-9.

Yeum, J. H., Park, J. H., Kim, I. K., \& Cheong, I. W. (2011), "Electrospinning Fabrication and Characterization of Water Soluble Polymer/Montmorillonite/Silver Nanocomposite Nanofibers out of Aqueous Solution", Advances in Nanocomposites - Synthesis, Characterization and Industrial Applications, 483-502.

Zhang, C., Yuan, X., Wu, L., Han, Y., \& Sheng, J. (2005), "Study on Morphology of Electrospun Poly(vinyl alcohol) Mats", European Polymer Journal 41(3), 423-432. 


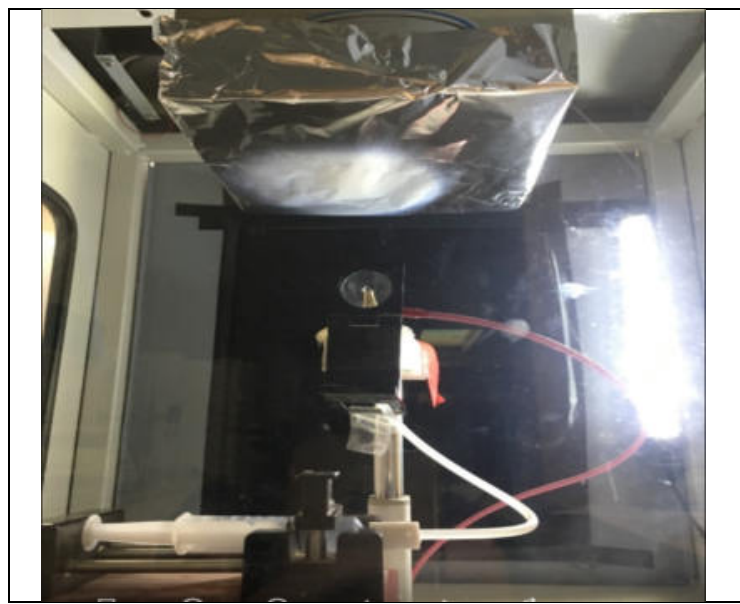

Figure 1. Electrospinning machine used in the study

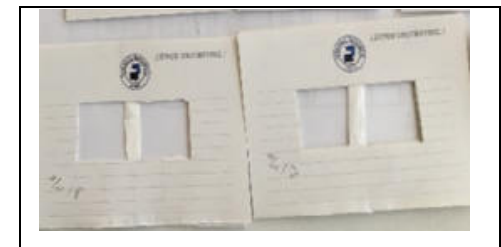

Figure 2. Preparation of nanofibrous samples for tensile testing 


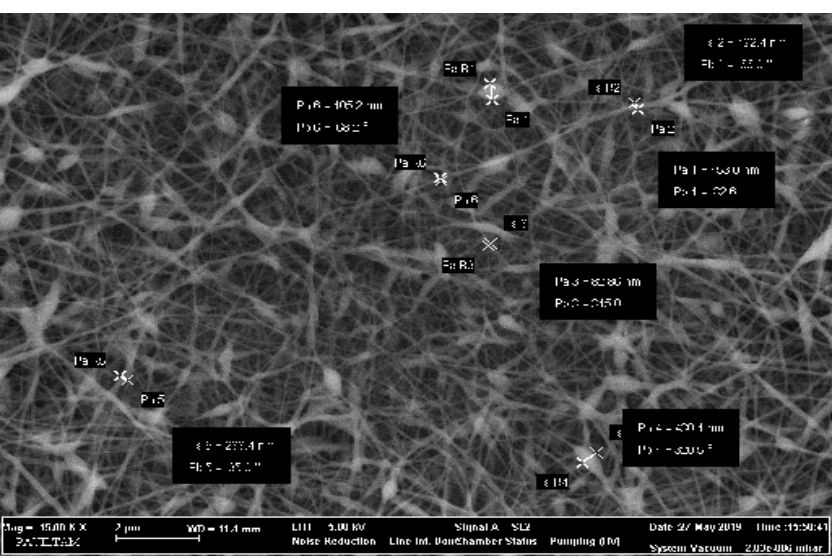

(a)

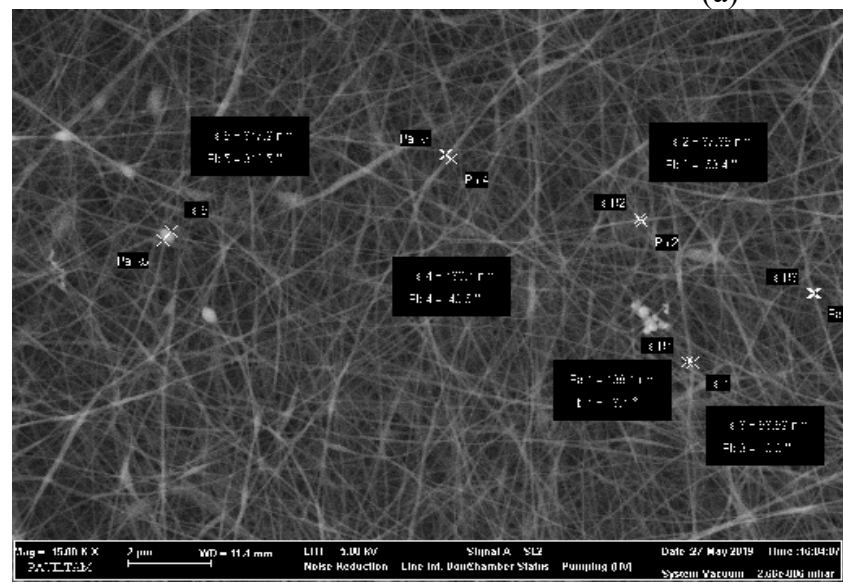

(b)

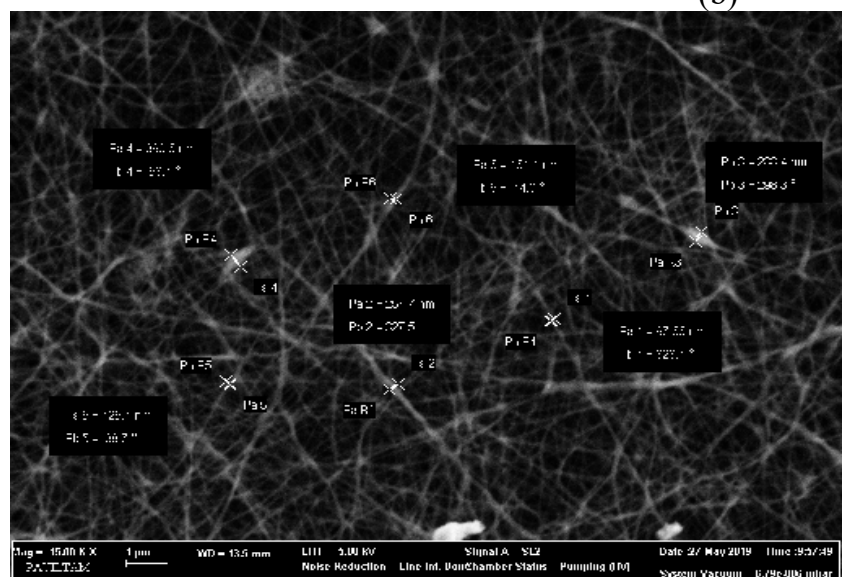

(c)

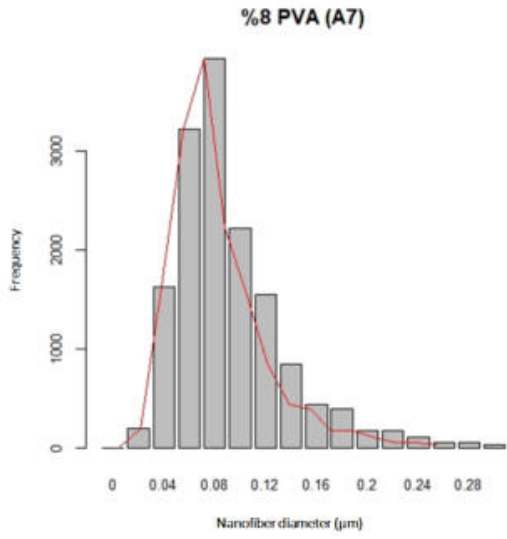

$\% 10$ PVA (B7)

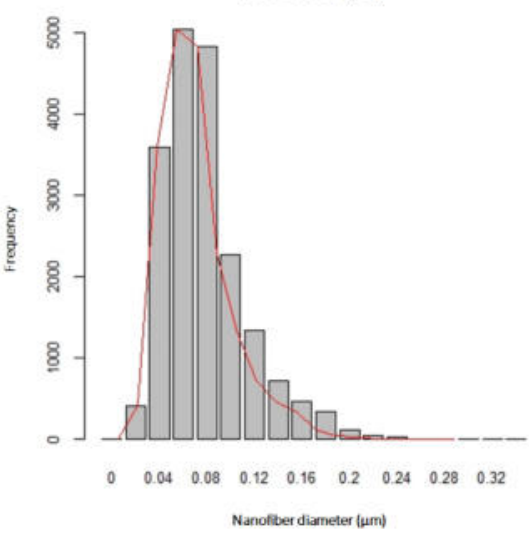

$\% 12$ PVA (C5)

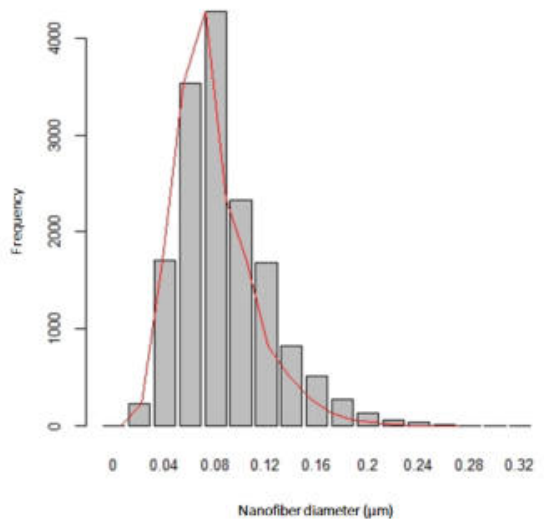

Figure 3. FESEM images and fiber diameter distribution graphs of samples A7 (a), B7 (b), C5(c) 


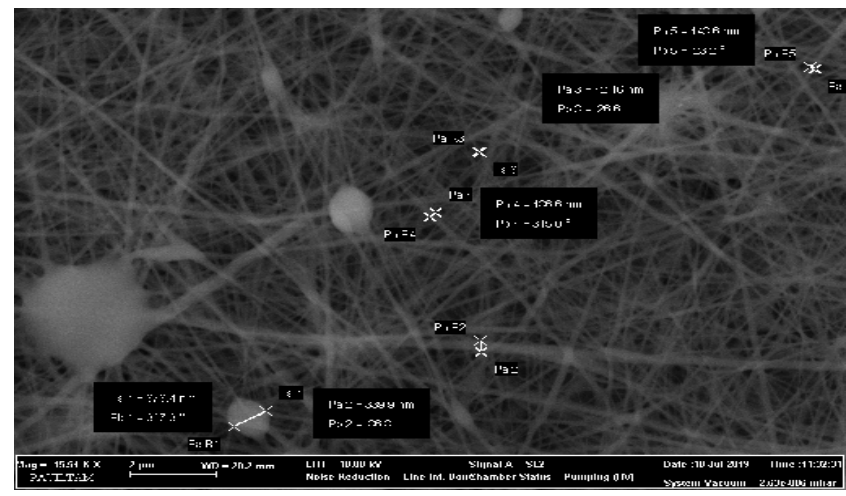

(a)

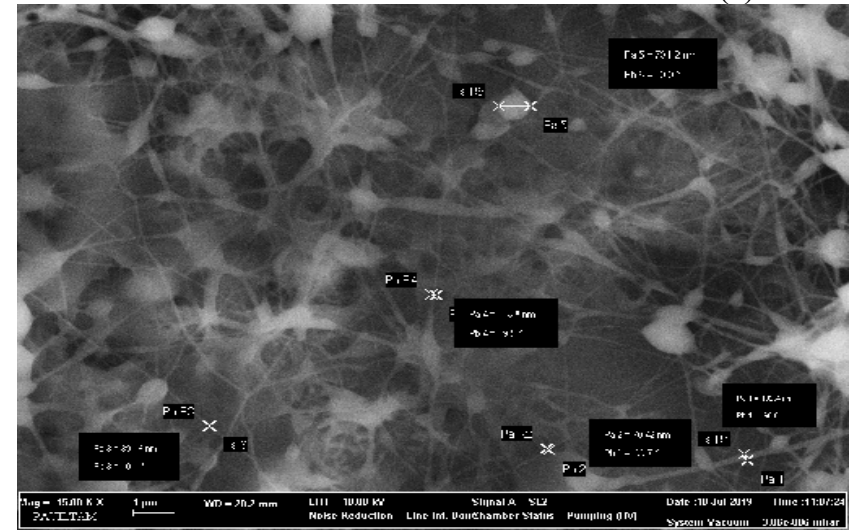

(b)

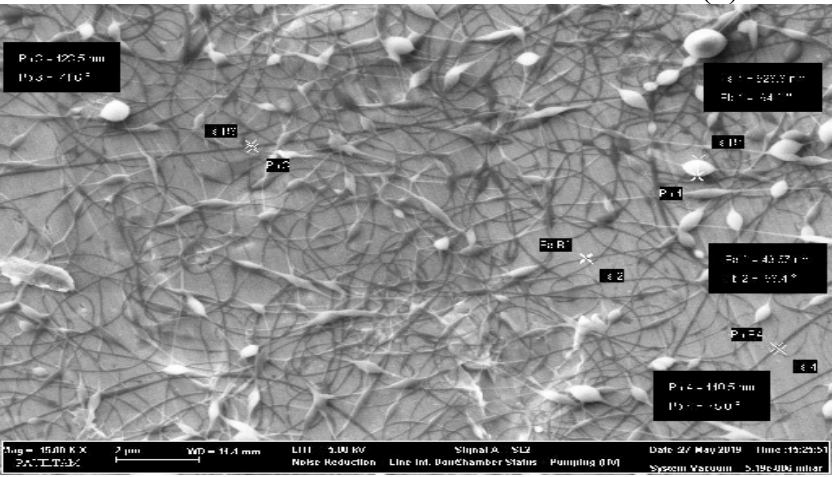

(c)

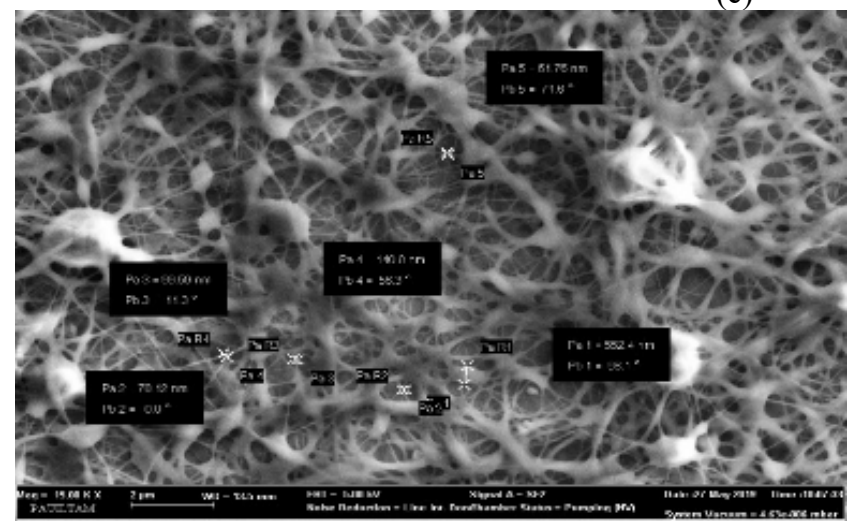

(d)

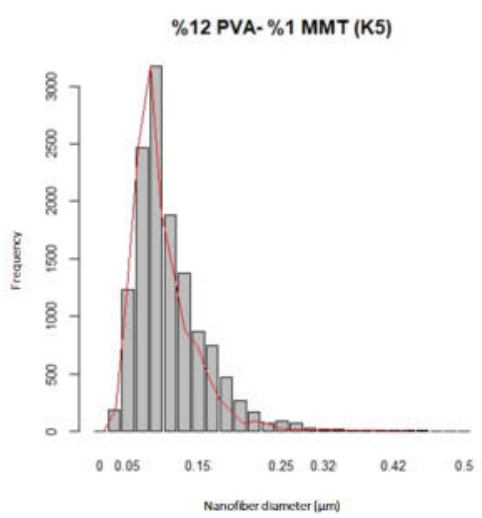

\%10 PVA- \%1 MMT (H1)



$\% 8$ PVA- $\% 1$ MMT (G7)

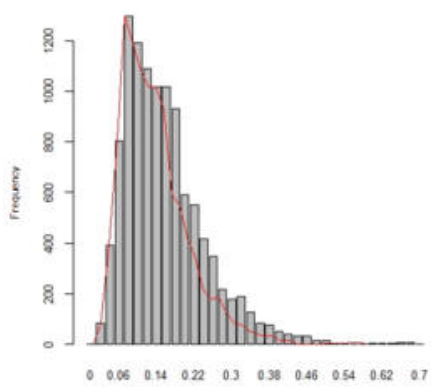

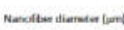

$\% 10$ PVA- $\% 2$ MMT (11)

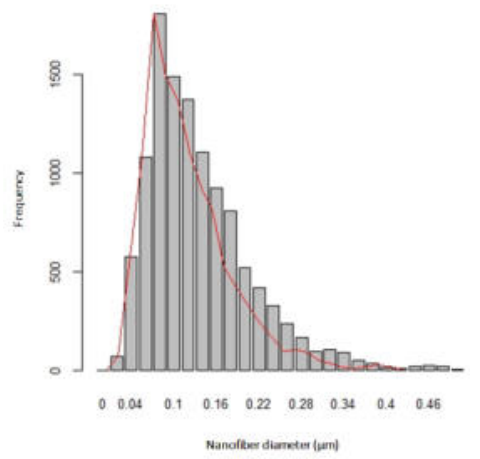

Figure 4. FESEM images and fiber diameter distributions graphs of samples K5(a), H2(b), G7(c), I1(d) 


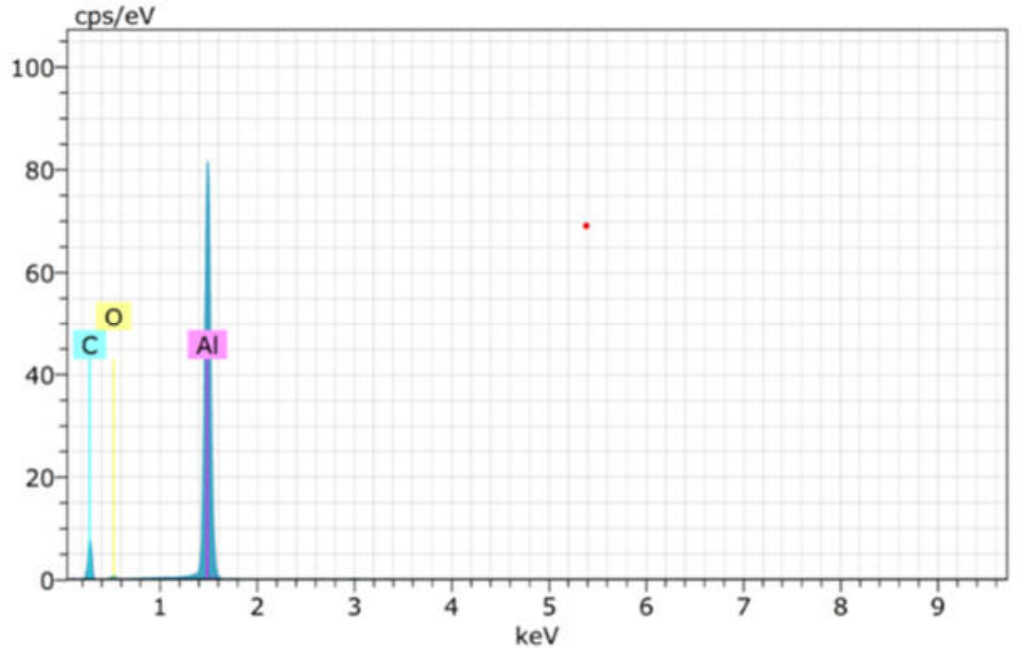

(a)

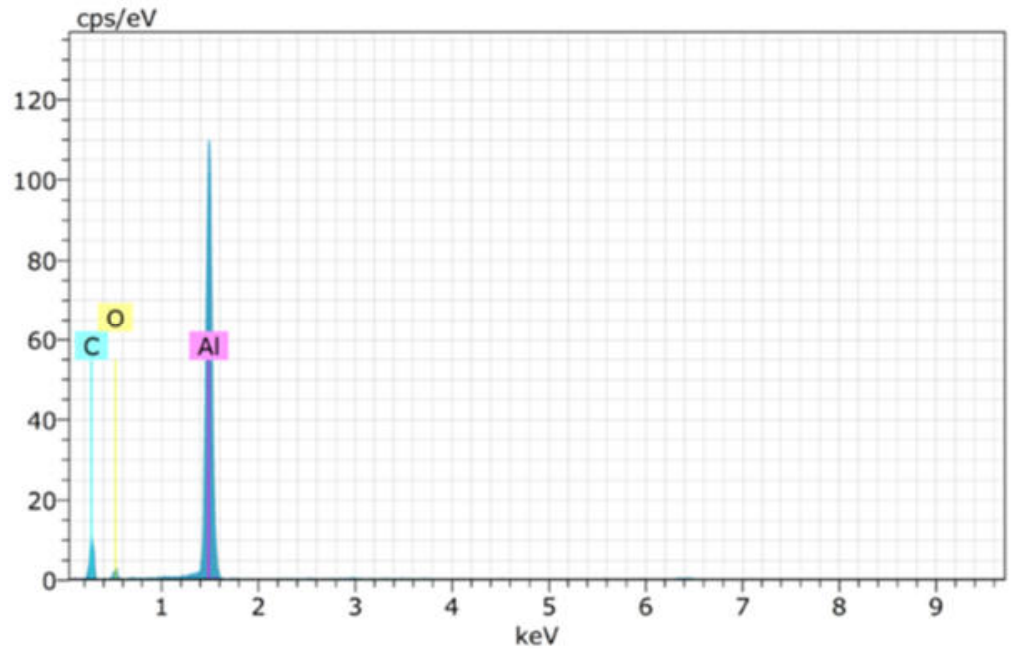

(b)

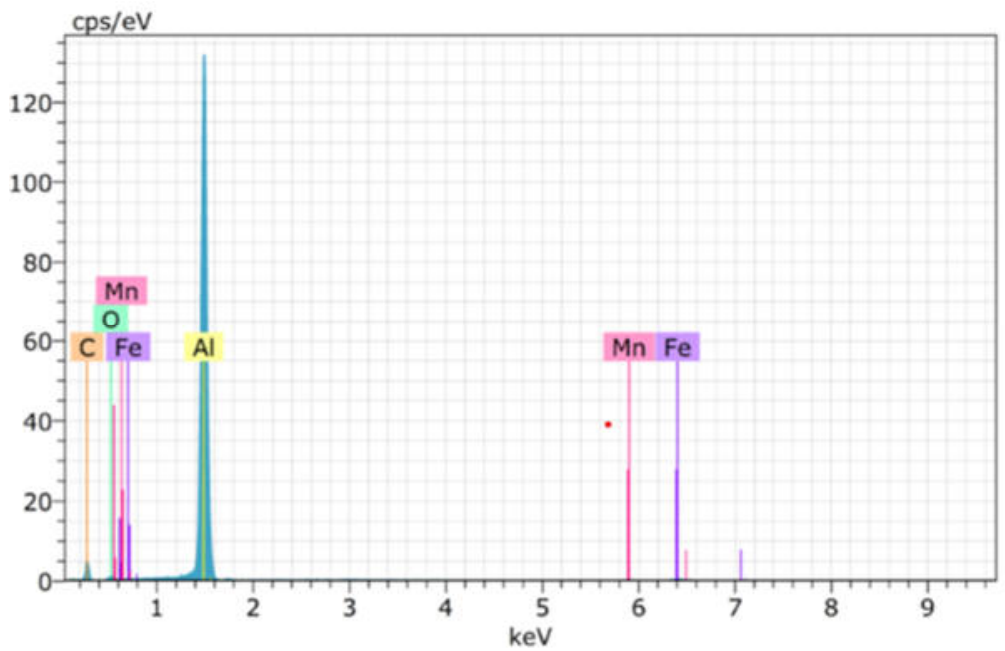

(c) 


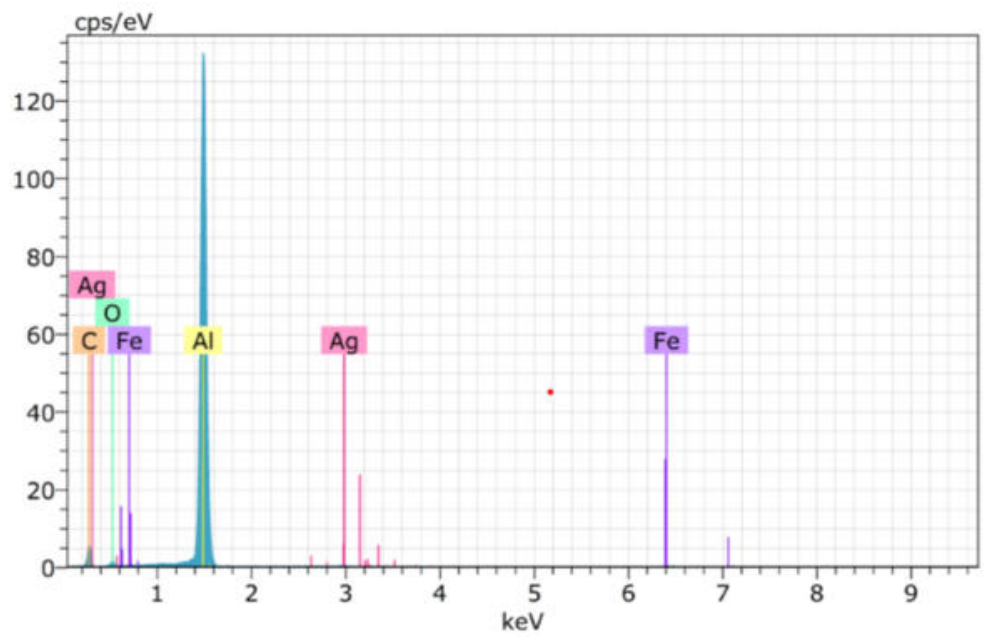

(d)

Figure 5. EDX analysis of (a) $18 \mathrm{wt} \%$ mechanically stirred PVA solution on aluminum substrate, (b) nanofibrous mat electrospun from $18 \mathrm{wt} \%$ mechanically stirred PVA solution, (c) mechanically stirred $1 \mathrm{wt} \%$ nanoclay added $18 \mathrm{wt} \%$ PVA solution and (d) sample deposited on aluminum foil from mechanically stirred 18 wt $\%$ PVA- 2 wt \% nanoclay

Table 1: Weight percentages of polymer and water in PVA solutions used in the study

\begin{tabular}{llll} 
Solution Code & PVA weight $\%$ & Distilled water $(g)$ & PVA (g) \\
\hline solA & $8 \mathrm{wt} \%$ & 92 & 8 \\
solB & $10 \mathrm{wt} \%$ & 90 & 10 \\
solC & $12 \mathrm{wt} \%$ & 88 & 12 \\
\hline
\end{tabular}

Table 2: Percentages in mechanically prepared nanoclay-PVA solutions

\begin{tabular}{lcllrrr}
$\begin{array}{l}\text { Code of } \\
\text { Solution }\end{array}$ & $\begin{array}{l}\text { PVA wt \% } \\
\text { in solution }\end{array}$ & $\begin{array}{l}\text { Nanoclay } \\
\text { wt \% in } \\
\text { solution }\end{array}$ & $\begin{array}{l}\text { Nanoclay wt\% } \\
\text { / final fiber weight }\end{array}$ & $\begin{array}{l}\text { Distilled } \\
\text { water (g) }\end{array}$ & $\begin{array}{l}\text { PVA } \\
\text { (g) }\end{array}$ & $\begin{array}{l}\text { Nanoclay } \\
(\mathbf{g})\end{array}$ \\
\hline $\mathrm{K}$ & $12 \mathrm{wt} \%$ & $1 \mathrm{wt} \%$ & $1 / 13$ & 87 & 12 & 1 \\
$\mathrm{H}$ & $10 \mathrm{wt} \%$ & $1 \mathrm{wt} \%$ & $1 / 11$ & 89 & 10 & 1 \\
$\mathrm{G}$ & $8 \mathrm{wt} \%$ & $1 \mathrm{wt} \%$ & $1 / 9$ & 91 & 8 & 1 \\
$\mathrm{I}$ & $10 \mathrm{wt} \%$ & $2 \mathrm{wt} \%$ & $1 / 6$ & 88 & 10 & 2 \\
\hline
\end{tabular}


Table 3: Viscosity and electrical conductivities of pure PVA solutions

\begin{tabular}{ccccc}
$\begin{array}{c}\text { Solution } \\
\text { Code }\end{array}$ & PVA wt \% & Viscosity $(\mathbf{c P})$ & $\begin{array}{c}\text { Surface tension } \\
(\mathbf{d y n e} / \mathbf{c m})\end{array}$ & $\begin{array}{c}\text { Electrical conductivity } \\
(\boldsymbol{\mu} / \mathbf{c m})\end{array}$ \\
\hline solA & $8 \mathrm{wt} \%$ & 84.0 & 61.12 & 0.85 \\
solB & $10 \mathrm{wt} \%$ & 137.6 & 59.97 & 0.87 \\
solC & $12 \mathrm{wt} \%$ & 221.0 & 58.17 & 0.88 \\
\hline
\end{tabular}

Table 4a: Viscosity and electrical conductivities of mechanically prepared nanoclay-PVA solutions

\begin{tabular}{cllcccc}
$\begin{array}{c}\text { Solution } \\
\text { Code }\end{array}$ & $\begin{array}{c}\text { PVA wt \% } \\
\text { in solution }\end{array}$ & $\begin{array}{l}\text { Nanoclay } \\
\text { wt \% in } \\
\text { solution }\end{array}$ & $\begin{array}{c}\text { Nanoclay } \\
\text { wt\% in final } \\
\text { web weight }\end{array}$ & Viscosity $(\mathbf{c P})$ & $\begin{array}{c}\text { Surface tension } \\
(\text { dyne/cm) }\end{array}$ & $\begin{array}{c}\text { E. conductivity } \\
(\boldsymbol{\mu S} / \mathbf{c m})\end{array}$ \\
\hline solK & $12 \mathrm{wt} \%$ & $1 \mathrm{wt} \%$ & $1 / 13$ & 189.1 & 57.34 & 1.06 \\
solH & $10 \mathrm{wt} \%$ & $1 \mathrm{wt} \%$ & $1 / 11$ & 107.0 & 58.24 & 0.89 \\
solG & $8 \mathrm{wt} \%$ & $1 \mathrm{wt} \%$ & $1 / 9$ & 82.4 & 57.13 & 0.85 \\
solI & $10 \mathrm{wt} \%$ & $2 \mathrm{wt} \%$ & $1 / 6$ & 111.0 & 59.26 & 1.05 \\
\hline
\end{tabular}

Table 4b: Viscosity and electrical conductivities with nanoclay addition

\begin{tabular}{|c|c|c|c|c|c|}
\hline $\begin{array}{l}\text { Solution } \\
\text { Code }\end{array}$ & $\begin{array}{l}\text { PVA wt \% } \\
\text { in solution }\end{array}$ & $\begin{array}{l}\text { Nanoclay } \\
\text { wt \% in } \\
\text { solution }\end{array}$ & $\begin{array}{l}\text { Nanoclay wt } \% \text { in } \\
\text { final web weight }\end{array}$ & Viscosity (cP) & $\begin{array}{l}\text { Electrical conductivity } \\
(\mu \mathrm{S} / \mathrm{cm})\end{array}$ \\
\hline solC & $12 \mathrm{wt} \%$ & - & - & 221.0 & 0.88 \\
\hline solK & 12 wt $\%$ & $1 \mathrm{wt} \%$ & $1 / 13$ & 189.1 & 1.06 \\
\hline solB & 10 wt $\%$ & - & - & 137.6 & 0.87 \\
\hline solH & $10 \mathrm{wt} \%$ & $1 \mathrm{wt} \%$ & $1 / 11$ & 107.0 & 0.89 \\
\hline solI & 10 wt $\%$ & 2 wt $\%$ & $1 / 6$ & 111.0 & 1.05 \\
\hline solA & 8 wt $\%$ & - & - & 84.0 & 0.85 \\
\hline solG & 8 wt $\%$ & $1 \mathrm{wt} \%$ & $1 / 9$ & 82.4 & 0.85 \\
\hline
\end{tabular}

Table 5: Nanofiber average diameters of pure PVA nanofibrous samples

\begin{tabular}{|c|c|c|c|c|c|c|}
\hline $\begin{array}{l}\text { Sample } \\
\text { code }\end{array}$ & $\begin{array}{l}\text { Applied voltage } \\
(\mathrm{kV})\end{array}$ & $\begin{array}{l}\text { Distance } \\
\text { (cm) }\end{array}$ & $\begin{array}{l}\text { Flow rate } \\
(\mathrm{ml} / \mathrm{h})\end{array}$ & $\begin{array}{l}\text { Average diameter } \\
(\mathrm{nm})\end{array}$ & $\begin{array}{l}\text { Nanofiber } \\
\text { appearance }\end{array}$ & $\begin{array}{l}\text { Standard } \\
\text { deviation }\end{array}$ \\
\hline A7 & 25 & 10 & 0.1 & 160.5 & $\begin{array}{l}\text { Large round shaped } \\
\text { and many beads }\end{array}$ & 0.621 \\
\hline B7 & 25 & 10 & 0.1 & 135.8 & $\begin{array}{l}\text { Very few and } \\
\text { ribboned beads }\end{array}$ & 0.536 \\
\hline C5 & 24 & 10 & 0.1 & 154.5 & $\begin{array}{l}\text { Smooth fibers, no } \\
\text { beads }\end{array}$ & 0.580 \\
\hline
\end{tabular}


Table 6: Nanofiber average diameters of nanoclay reinforced PVA nanofibrous samples

\begin{tabular}{|c|c|c|c|c|c|c|}
\hline $\begin{array}{l}\text { Sample } \\
\text { code }\end{array}$ & $\begin{array}{l}\text { Applied voltage } \\
(\mathrm{kV})\end{array}$ & $\begin{array}{l}\text { Distance } \\
\text { (cm) }\end{array}$ & $\begin{array}{l}\text { Flow rate } \\
(\mathrm{ml} / \mathrm{h})\end{array}$ & $\begin{array}{l}\text { Average diameter } \\
(\mathrm{nm})\end{array}$ & $\begin{array}{l}\text { Nanofiber } \\
\text { appearance }\end{array}$ & $\begin{array}{l}\text { Standard } \\
\text { deviation }\end{array}$ \\
\hline K5 & 30 & 10 & 0.1 & 155.9 & $\begin{array}{l}\text { Smooth fibers, } \\
\text { no beads }\end{array}$ & 0.635 \\
\hline H1 & 30 & 7,5 & 0.1 & 244.8 & $\begin{array}{l}\text { Characteristic } \\
\text { large beads }\end{array}$ & 0.139 \\
\hline G7 & 32 & 10 & 0.1 & 260.0 & $\begin{array}{l}\text { Characteristic } \\
\text { large beads }\end{array}$ & 0.140 \\
\hline I1 & 25 & 10 & 0.1 & 221.7 & $\begin{array}{l}\text { Networks with } \\
\text { large beads }\end{array}$ & 0.111 \\
\hline
\end{tabular}

Table 7: Tensile test results of nanoclay (MMT) reinforced nanofibrous mats from stirred solutions

\begin{tabular}{llllrr}
$\begin{array}{l}\text { PVA wt \% } \\
\text { in solution }\end{array}$ & $\begin{array}{l}\text { Nanoclay wt \% } \\
\text { in solution }\end{array}$ & $\begin{array}{l}\text { Mixing } \\
\text { method }\end{array}$ & $\begin{array}{l}\text { Nanoclay wt\% in fiber } \\
\text { total weight }\end{array}$ & Force (N) & Elongation (\%) \\
\hline 18 wt \% & - & mechanical & 0 & $2.85 \pm 0.2$ & $3.80 \pm 0.5$ \\
18 wt $\%$ & 1 wt $\%$ & mechanical & $1 / 19$ & $2.00 \pm 0.3$ & $8.75 \pm 0.8$ \\
18 wt \% & 2 wt $\%$ & mechanical & $1 / 10$ & $2.15 \pm 0.3$ & $13.20 \pm 1.5$ \\
18 wt $\%$ & 3 wt $\%$ & mechanical & $1 / 7$ & $1.15 \pm 0.2$ & $5.22 \pm 0.7$ \\
\hline
\end{tabular}

